\title{
Rol del cuidador familiar novel de adultos en situación de dependencia: Scoping Review
}

\author{
Role of Novice Family Caregivers of Dependent Adults: A Scoping \\ Review
}

Papel do novo cuidador familiar de adultos em situação de dependência: Scoping Review

Como citar este artículo:

Esquivel Garzón Natalia, Carreño Moreno Sonia, Chaparro Díaz Lorena Rol del cuidador familiar novel de adultos en situación de dependencia: scoping review. Revista Cuidarte. 2021;12 2 :e1368.

http://dx.doi.org/10.15649/cuidarte.1368

Revista Cuidarte

Rev Cuid. May - Ago 2021; 12(2): e1368

doij http://dx.doi.org/10.15649/cuidarte.1368

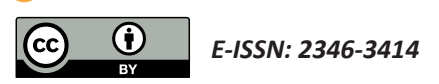

๑ Natalia Esquivel Garzón'

(1) Sonia Carreño Moreno²

๑ Lorena Chaparro Díaz

1 Doctora en Enfermería. Profesora, Facultad Ciencias de la Salud, programa de enfermería, grupo de investigación Cuidado en Salud, Universidad Libre. Cali, Colombia. E-mail: natalia.esquivelg@unilibre. edu.co Autora Correspondencia

2 Doctora en Enfermería. Profesora asociada, Facultad de Enfermería, Universidad Nacional de Colombia. Bogotá, Colombia.

E-mail: spcarrenom@unal.edu.co

3 Doctora en Enfermería. Profesora asociada, Facultad de Enfermería, Universidad Nacional e Colombia. Bogotá, Colombia.

E-mail: olchaparrod@unal.edu.co

\section{Resumen}

Introducción: El incremento del número de personas adultas, en situación de dependencia, discapacidad y con necesidades de cuidado, ha generado el surgimiento de los cuidadores familiares, quienes asumen esta responsabilidad, sin la formación o conocimientos previos, situación que puede comprometer el desempeño de este nuevo rol y sus resultados en el receptor de cuidado. Materiales y Métodos: Se realizó un Scoping Review con la metodología de Arksey y O’Malley, que incluyó la revisión de los estudios disponibles en bases de datos en línea, en idioma inglés y español, a partir de lo cual se extrajo información relacionada con la asunción del rol de cuidador familiar novel de adultos en situación de dependencia. Resultados: Se incluyeron un total de 42 artículos y surgieron cinco temas; que incluyen, las tendencias sociodemográficas, la trayectoria y dinámicas a lo largo del tiempo, las transiciones que implica el nuevo rol, la participación en la toma de decisiones y los dominios e impactos en quien ejerce el cuidado. Discusión: Se evidenció que ejercer el rol de cuidador familiar novel de personas en situación de dependencia, implica adquirir una serie de competencias, conocimientos, y habilidades, además; de requerir un adecuado soporte social, aspectos que deben ser explorados, reconocidos y abordados por Enfermería. Conclusiones: Este estudio proporciona información para comprender las experiencias e implicaciones que tiene convertirse en cuidador novel, de forma que los profesionales de la salud adapten las intervenciones destinadas a apoyar a los cuidadores y mejorar su bienestar.

Palabras clave: Cuidador Familiar; Personas con Discapacidad; Adulto; Cuidadores; Experiencias de Vida

Recibido: 11 de julio de 2020

Aceptado: 2 de febrero de 2021

Publicado: 24 de mayo de 2021 $\square *$ Correspondencia Natalia Esquivel Garzón E-mail: natalia.esquivelg@unilibre.edu.co 


\section{Role of Novice Family Caregivers of Dependent Adults: A Scoping Review}

\section{Abstract}

Introduction: An increase in the number of adults with dependencies, disabilities or care needs has led to the emergence of family caregivers, who regularly assume this responsibility without any previous training or knowledge, which may result in compromising their performance in this new role and their outcomes in care recipients. Materials and Methods: A scoping review was conducted following Arksey and O'Malley's scoping framework, which included the review of studies in English and Spanish that are available in online databases to extract the information related to the adoption of the role of novice family caregiver of dependent adults. Results: A total of 42 articles was selected from which five major themes were identified, including sociodemographic trends, course and dynamics over time, transitions involved in this new role, participation in decision making, and domains and impacts on caregivers. Discussion: Performing the role of a novice family caregiver of dependent adults involves acquiring a series of competencies, knowledge and skills, as well as requiring adequate social support, all of which are aspects that should be explored, recognized and addresses by nursing professionals. Conclusions: This study provides information to understand the experiences and implications of becoming a novice caregiver, thus enabling healthcare professionals to adapt interventions aimed to support caregivers and improve their well-being.

Key word: Family Caregiver; Disabled Persons; Adult; Caregivers; Lived Experience

\section{Papel donovo cuidador familiar de adultosem situação de dependência: Scoping Review}

\section{Resumo}

Introdução: O aumento do número de adultos, em situação de dependência, incapacidade e com necessidades de cuidados, tem gerado o surgimento de cuidadores familiares, que assumem essa responsabilidade, sem formação ou conhecimento prévio, situação que pode comprometer o desempenho deste novo papel e seus resultados no recebedor de cuidados. Materiais e Métodos: Foi realizada uma Scoping Review com a metodologia de Arksey e O'Malley, que incluiu uma revisão dos estudos disponíveis em bases de dados on-line, nos idiomas inglês e espanhol, de onde foram extraídas informações relacionadas à aceitação do papel como novo cuidador familiar de adultos em situação de dependência. Resultados: Foram incluídos um total de 42 artigos e surgiram cinco temas; que incluem as tendências sociodemográficas, a trajetória e dinâmica ao longo do tempo, as transições implicadas pelo novo papel, a participação na tomada de decisões e os domínios e impactos em quem exerce cuidado. Discussão: Evidenciou-se que o exercício da função de novo cuidador familiar de pessoas em situação de dependência implica em adquirir uma série de competências, conhecimentos e habilidades, além disso; de exigir suporte social adequado, aspectos que devem ser explorados, reconhecidos e abordados pela Enfermagem. Conclusões: Este estudo fornece informações para compreender as experiências e implicações de se tornar um cuidador iniciante, de forma que os profissionais de saúde adaptem as intervenções destinadas a apoiar aos cuidadores e melhorar seu bem-estar.

Palavras clave: Cuidador Familiar; Pessoas com Deficiências; Adulto; Cuidadores; Experiências de Vida 


\section{Introducción}

Para la disciplina de enfermería, es importante abordar las necesidades del cuidador familiar novel, partiendo del conocimiento del entorno en el cual surge la demanda de cuidado, las condiciones individuales del paciente, su medio familiar, social y cultural, en un contexto de interacción recíproca, confianza mutua y comunicación asertiva, de forma que durante la fase inicial de la experiencia como cuidador, encuentre un significado y adquiera las competencias instrumentales, emocionales, sociales y espirituales, requeridas para ejercer su rol en la cotidianidad ${ }^{1,2}$. En el presente artículo se revisarán aspectos propios del rol de cuidador familiar novel, entendiéndose este, como aquella persona que asume por primera vez, el cuidado integral de un individuo con dependencia y lo hace sin la formación o conocimientos previos.

La dependencia, se define como el estado en el que una persona presenta una limitación o imposibilidad para realizar actividades básicas e instrumentales de la vida diaria y requiere de la asistencia de un tercero para suplir estos requerimientos, en general por periodos prolongados; se relaciona directamente con el grado de discapacidad o disminución de la capacidad funcional y /o mental, de modo que a mayor gravedad de la discapacidad mayor es la probabilidad de dependencia ${ }^{3}$. La discapacidad severa o grave, caracterizada por el alto compromiso funcional y gran dependencia de un cuidador, afecta alrededor del 15\% de la población mundial, si bien abarca toda la estructura de edades, se concentra especialmente en las personas mayores de 75 años ${ }^{4}$.

A nivel mundial la esperanza de vida y los años de vida saludables se han incrementado, como lo han hecho los años de vida con incapacidad, como consecuencia de la elevada prevalencia de enfermedades crónicas en las personas mayores, cuya afectación es alta en países con bajos y medios ingresos 5 . Para el caso de los países latinoamericanos, han experimentado una acelerada transición demográfica y epidemiológica ${ }^{6}$, aumentando el número de personas dependientes que requieren cuidados prolongados y necesitan de asistencia desde los sistemas formales e informales ${ }^{7}$. En Colombia el $2.4 \%$ de la población general presenta discapacidad; sin embargo, este comportamiento no es homogéneo a lo largo de la vida, pues se presenta en forma directamente proporcional con el incremento de la edad, de forma que alcanza el $29.7 \%$, en los mayores de 80 años; se ha determinado que el $40 \%$ de estas personas necesitan ayuda de otras personas; de ellas el $88 \%$ la reciben de un familiar y en un $82 \%$ son las mujeres quienes proveen principalmente el cuidado ${ }^{8}$.

La responsabilidad de cuidar, puede ser asumida por un cuidador familiar, quien en general posee un vínculo con el receptor del cuidado, esto es un padre, los hijos, el cónyuge o tiene alguna cercanía con la persona que es cuidada; su trabajo tiene gran relevancia, no sólo por la atención directa al paciente, sino por el papel en la reorganización, mantenimiento, cohesión de la familia, toma de decisiones, cubrimiento de las necesidades básicas y la superación de la vulnerabilidad por la enfermedad ${ }^{9}$.

Pasar de ser el familiar o amigo cercano de una persona previamente sana, a ser un cuidador familiar, implica la transición hacia un nuevo rol, que en ocasiones se asume de forma progresiva, 
pero en otras surge de forma repentina e inesperada, y constituye una situación para la cual no se está preparado ${ }^{10}$. La persona que asume el rol de cuidador novel, se hace cargo de gran cantidad de tareas, que la colocan en una situación de vulnerabilidad, ya que ha de proveer cuidados durante meses e incluso años, lo que puede generar resultados desfavorables, tanto para él, como para el receptor de los cuidados. La carga del cuidado, afecta en quien la ejerce, sus dimensiones como ser humano, pues ocasiona cambios en el estilo de vida, en la salud física, emocional y mental, representados en disminución de la calidad de vida, ansiedad, depresión, estrés y cambios en el estado de ánimo ${ }^{11}$.

Para cumplir con su rol y lograr mantener su propia salud, seguridad y bienestar, los cuidadores familiares, necesitan de reconocimiento, información y apoyo de los sistemas sociales y de salud, ya que las necesidades de las personas dependientes, derivadas de sus condiciones de salud son variables y complejas, y es en el cuidador en quien reside el compromiso de preservar la integridad del otro ${ }^{12}$.

Por lo anterior, el profesional de enfermería, debe identificar e integrar el conocimiento generado a partir de la experiencia y el análisis de la evidencia científica, de forma que se pueda responder de forma adecuada a las necesidades de la persona dependiente, abordando las competencias de quienes los cuidan, brindando soporte y cuidado al cuidador, especialmente a quienes realizan esta labor de manera informal. Teniendo en cuenta lo anterior, esta revisión tuvo como objetivo, mapear la evidencia publicada sobre el rol del cuidador familiar novel, en lo relacionado con su perfil, trayectoria del cuidado, transición e impacto del rol.

\section{Método}

Se realizó un Scoping Review, este tipo de enfoque metodológico es una forma de mapear y sintetizar el conocimiento alrededor de una pregunta específica de investigación, a partir de la selección y síntesis sistemática de la literatura, con el propósito de dar una mayor claridad conceptual sobre un tema o campo específico de investigación y proporcionar evidencia para la práctica, la investigación y la formulación de políticas. Para su realización, se siguieron las cinco etapas propuestas por Arksey y $\mathrm{O}^{\prime}$ Malley $^{13}$, que incluyen: i) identificación de la pregunta de investigación, ii) identificación de estudios relevantes, iii) selección de estudios apropiados, iv) graficación y registro de datos y v resumen y presentación de resultados.

Paso 1: la pregunta de investigación que guio el Scoping Review fue: ¿Cuáles son las características individuales y cómo es el proceso con el que se asume el rol de cuidador familiar novel, de adultos en situación de dependencia?

\section{Paso 2: fuentes de información y búsqueda de literatura}

La identificación de artículos se llevó a cabo mediante un proceso de búsqueda y análisis de la literatura durante los meses de enero a marzo de 2020, en las siguientes bases de datos: Pubmed/Medline, Science Direct, Scopus, SCIELO, CINHAL, CUIDEN, y Wiley Online Library. Por su parte, se utilizaron los siguientes términos de búsqueda en español e inglés: "cuidador", "caregiver", "adulto", "adult", "dependencia" "dependence", "discapacidad", "disability", "cuidador informal", "informal caregiver", "rol del cuidador", "carer role"; "diagnóstico temprano", "early diagnosed", "cuidador familiar" "family caregiving"; con los cuales se realizaron combinaciones con los operadores booleanos AND, NOT, OR. En la búsqueda sistemática, se excluyó la literatura no convencional tesis, actas de congresos, informes, memorias, separatas, weblogs etc. 


\section{Criterios de elegibilidad}

Los criterios de selección fueron: i) artículo publicado en revista indexada en fuentes de conocimiento de calidad, ii) idioma español o inglés, iii) disponibles en texto completo, iv) cuidador mayor de 18 años, v) cuidador que ejerciera el rol por primera vez, vi) hallazgos relacionados con la pregunta de investigación. En cuanto a los criterios de exclusión, se establecieron los siguientes: estudios cuya población a atender además de adultos incluyera adolescentes o niños.

Paso 3: para la selección de los artículos se realizó la revisión del título, el cual debía contener al menos dos de las palabras claves ${ }^{14}$. Esta primera estrategia de búsqueda identificó 2536 documentos y posteriormente se procedió a leer el resumen aplicando los criterios de inclusión y exclusión; aquellos identificados como potencialmente elegibles fueron leídos por completo. Los resultados de la búsqueda se presentan en la Figura 1.

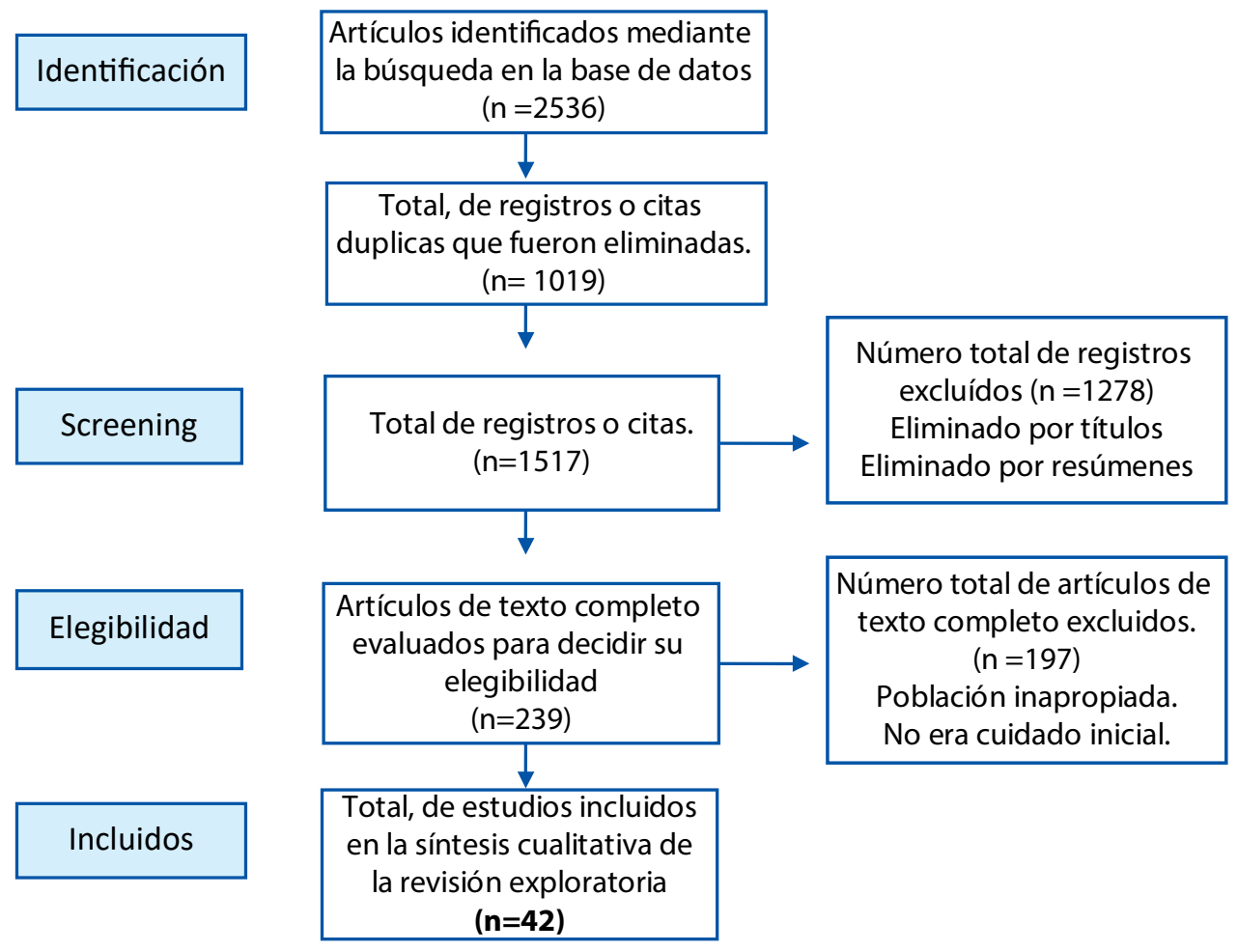

Figura 1. Búsqueda sistemática de literatura y proceso de selección de artículos

\section{Evaluación de la calidad metodológica}

Se realizó una evaluación de los estudios bajo los criterios de las guías de lectura crítica CASPe y Equator Network ${ }^{15}$, los cuales evalúan criterios de validez, fiabilidad y aplicabilidad según tipo de estudio. La lectura crítica, se llevó a cabo de manera separada por parte de dos revisores cegados, posteriormente entre las autoras se discutieron las discrepancias para la selección final de los artículos.

Paso 4: para estandarizar el proceso de extracción de datos relevantes, se realizó un resumen estructurado y lógico en un archivo de Microsoft Excel, que incluyó las siguientes categorías de información: autor (es), año de publicación, país, objetivo del estudio, población/muestra, metodología y principales hallazgos.

Paso 5: para identificar los temas y patrones que prevalecieron en los estudios, se recopiló la información extraída de los artículos y se asignaron categorías analíticas, congruentes con el 
área de interés. Los estudios no fueron ponderados por el tamaño de la muestra o el diseño de la investigación, pero en su lugar fueron revisados y agrupados temáticamente ${ }^{16,17}$.

\section{Resultados}

Como resultados del Scoping Review realizada en seis bases de datos, en la Tabla 1 se presentan las características generales de los estudios identificados.

\section{Tabla 1. Resumen de los artículos seleccionados}

\begin{tabular}{|c|c|c|c|c|}
\hline Autor & $\begin{array}{l}\text { Año/ } \\
\text { País }\end{array}$ & Objetivo & $\begin{array}{l}\text { Situación de } \\
\text { dependencia }\end{array}$ & Rol del cuidador Familiar \\
\hline \multicolumn{5}{|c|}{ Tema: Perfil de las personas que asumen el rol del cuidador familiar novel } \\
\hline $\begin{array}{l}\text { Wolff, } \\
\text { Jennifer } \\
\text { et al. }\end{array}$ & $\begin{array}{l}\text { 2016/ } \\
\text { EEUU }\end{array}$ & $\begin{array}{l}\text { Examinar cómo la participación } \\
\text { de los cuidadores en las } \\
\text { actividades de atención médica } \\
\text { de los adultos mayores, se } \\
\text { relaciona con las } \\
\text { responsabilidades del cuidador, } \\
\text { el uso de servicios de apoyo y } \\
\text { los efectos relacionados con el } \\
\text { cuidado. }\end{array}$ & $\begin{array}{l}\text { Adultos mayores } \\
\text { con demencia } \\
\text { discapacidad } \\
\text { grave que viven } \\
\text { en la comunidad }\end{array}$ & $\begin{array}{l}\text { Asistencia en actividades relacionadas con la } \\
\text { atención médica, como transporte y visitas a los } \\
\text { servicios de salud, administración de } \\
\text { medicamentos y actividades del hogar }\end{array}$ \\
\hline $\begin{array}{l}\text { Pinquart, } \\
\text { Martín et } \\
\text { al. }\end{array}$ & $\begin{array}{l}\text { 2005/ } \\
\text { España }\end{array}$ & $\begin{array}{l}\text { Identificar las similitudes y } \\
\text { diferencias en las variables de } \\
\text { cuidado entre cuidadores } \\
\text { familiares en grupos étnicos } \\
\text { minoritarios. }\end{array}$ & $\begin{array}{l}\text { Adultos mayores } \\
\text { con limitación } \\
\text { física y personas } \\
\text { con demencia. }\end{array}$ & $\begin{array}{l}\text { Los cuidadores de minorías étnicas tenían una } \\
\text { edad media de } 57,9 \text { años, eran más jóvenes que los } \\
\text { cuidadores blancos tenían menos probabilidades } \\
\text { de ser cónyuges, estar casadosy reportar altos } \\
\text { niveles de educación e ingresos. }\end{array}$ \\
\hline $\begin{array}{l}\text { Toribio- } \\
\text { Díaz, ME } \\
\text { et al }\end{array}$ & $\begin{array}{c}\text { 2013/ } \\
\text { España }\end{array}$ & $\begin{array}{l}\text { Describir las características de } \\
\text { los pacientes con demencia en } \\
\text { la provincia de Alicante, así } \\
\text { como los perfiles y roles de los } \\
\text { cuidadores que les atienden. }\end{array}$ & $\begin{array}{l}\text { Pacientes con } \\
\text { demencia y } \\
\text { Alzheimer en un } \\
\text { estadio } \\
\text { moderadamente } \\
\text { grave }\end{array}$ & $\begin{array}{l}\text { Los cuidadores principales eran en su mayoría } \\
\text { mujeres la mayoría son amas de casa con bajo } \\
\text { nivel educativo, el } 64 \% \text { tenían un parentesco } \\
\text { hijos, quienes brindaban cuidado por obligación } \\
\text { moral. }\end{array}$ \\
\hline $\begin{array}{l}\text { Del-Pino- } \\
\text { Casado } \\
\text { Rafael et } \\
\text { al. }\end{array}$ & $\begin{array}{c}\text { 2012/ } \\
\text { España }\end{array}$ & $\begin{array}{l}\text { Describir las características de } \\
\text { los pacientes con demencia en } \\
\text { la provincia de Alicante, así } \\
\text { como los perfiles y roles de los } \\
\text { cuidadores que les atienden. }\end{array}$ & $\begin{array}{l}\text { Pacientes con } \\
\text { demencia y } \\
\text { Alzheimer en un } \\
\text { estadio } \\
\text { moderadamente } \\
\text { grave }\end{array}$ & $\begin{array}{l}\text { Los cuidadores principales eran en su mayoría } \\
\text { mujeres la mayoría son amas de casa con bajo } \\
\text { nivel educativo, el } 64 \% \text { tenían un parentesco } \\
\text { hijos, quienes brindaban cuidado por obligación } \\
\text { moral. }\end{array}$ \\
\hline $\begin{array}{l}\text { Schulz, } \\
\text { Richard } \\
\text { et al. }\end{array}$ & $\begin{array}{l}\text { 2012/ } \\
\text { EEUU }\end{array}$ & $\begin{array}{l}\text { Identificar los predictores y } \\
\text { consecuencias de la falta de } \\
\text { elección al asumir el rol de } \\
\text { cuidador. }\end{array}$ & $\begin{array}{l}\text { Adultos de } 50 \\
\text { años o más }\end{array}$ & $\begin{array}{l}\text { El } 68 \% \text { de los cuidadores fueron mujeres, el } 61 \% \\
\text { estaba cuidando aun padre, La mayoría de los } \\
\text { cuidadores estaban empleados fuera del hogar. Los } \\
\text { cuidadores mayores con un alto nivel educativo } \\
\text { que cuidan a un receptor de cuidados más joven } \\
\text { con problemas emocionales o de comportamiento, } \\
\text { tenían más probabilidades de informaque no } \\
\text { tenían otra opción para asumir el papel de } \\
\text { cuidadores. La falta de elección se asocia con } \\
\text { niveles más altos de estrés emocional, tensión } \\
\text { física e impactos negativos en la salud. El } 61 \% \\
\text { estaba cuidando a un padre. }\end{array}$ \\
\hline $\begin{array}{l}\text { Godfrey, } \\
\text { Wesley et } \\
\text { al. }\end{array}$ & $\begin{array}{l}\text { 2018/ } \\
\text { EEUU }\end{array}$ & $\begin{array}{l}\text { Describir el grado de acuerdo } \\
\text { diario, las percepciones sobre la } \\
\text { atención brindada y el cuidado } \\
\text { recibido entre las parejas de } \\
\text { adultos mayores. }\end{array}$ & Adultos mayores & $\begin{array}{l}\text { Los participantes tenían en promedio } 62,4 \text { años } \\
\text { rango }=60-64 \text { años cuidar a un cónyuge se } \\
\text { relacionó con una mayor satisfacción conyugal, } \\
\text { los cuidadores generalmente informan que brindan } \\
\text { una mayor atención si se compara con la } \\
\text { percepción que tienen los receptores de cuidado. }\end{array}$ \\
\hline
\end{tabular}




\begin{tabular}{|c|c|c|c|c|}
\hline Autor & $\begin{array}{l}\text { Año/ } \\
\text { País }\end{array}$ & Objetivo & $\begin{array}{l}\text { Situación de } \\
\text { dependencia }\end{array}$ & Rol del cuidador Familiar \\
\hline $\begin{array}{l}\text { Martins, } \\
\text { Gabriela } \\
\text { et al. }\end{array}$ & $\begin{array}{l}\text { 2019/ } \\
\text { Brasil }\end{array}$ & $\begin{array}{l}\text { Evaluar y comparar las } \\
\text { características } \\
\text { sociodemográficas, síntomas } \\
\text { depresivos, ansiedad y estrés } \\
\text { percibido de los cuidadores } \\
\text { formales e informales de } \\
\text { ancianos con enfermedad de } \\
\text { Alzheimer }\end{array}$ & $\begin{array}{l}\text { Adultos mayores } \\
\text { con enfermedad } \\
\text { de Alzheimer }\end{array}$ & $\begin{array}{l}\text { El } 96,2 \% \text { de los cuidadores fueron mujeres, con } \\
\text { una edad mediade } 52,9 \text { años, el } 65,4 \% \text { de los } \\
\text { cuidadorestenían como parentesco hijos, seguido } \\
\text { de las esposas enel } 19,2 \% \text {, el } 57,7 \% \text {, la mayoría } \\
\text { tenía } 9 \text { años o más de escolaridad. }\end{array}$ \\
\hline $\begin{array}{l}\text { Lüdecke, } \\
\text { Daniel } \\
\text { et al. }\end{array}$ & $\begin{array}{c}\text { 2012/ } \\
\text { Alemania }\end{array}$ & $\begin{array}{l}\text { Describir la situación de los } \\
\text { cuidadores familiares de } \\
\text { personas mayores dependientes } \\
\text { en Europa en términos de } \\
\text { existencia, sensibilización, } \\
\text { disponibilidad, uso y aceptación } \\
\text { de los servicios de apoyo }\end{array}$ & $\begin{array}{l}\text { Adultos con } 65 \\
\text { años o más }\end{array}$ & $\begin{array}{l}\text { Los cuidadores familiares tenían } 54 \text { años en } \\
\text { promedioDE }=13,4,76 \% \text { de ellos eran mujeres. } \\
\text { Las características sociodemográficas, la } \\
\text { percepción de carga del cuidador, la evaluación de } \\
\text { la necesidad de asistencia del familiar dependiente } \\
\text { influye en la búsqueda y usode los servicios de } \\
\text { salud. }\end{array}$ \\
\hline $\begin{array}{l}\text { Yakubu, } \\
\text { Yakubu, } \\
\text { A. et al. }\end{array}$ & $\begin{array}{c}\text { 2018/ } \\
\text { Sur África }\end{array}$ & Evaluar la carga del cuidador & Adultos mayores & $\begin{array}{l}\text { El } 49,5 \% \text { de las cuidadoras mujeres de raza negra } \\
\text { estaban en el grupo de edad de } 50 \text { a } 59 \text { años. El rol } \\
\text { de cuidador era una tarea a tiempo completo, ya } \\
\text { que una gran proporción brindaba cuidados } \\
\text { durante más de } 40 \text { horas por semana, sin } \\
\text { programas de cuidado deapoyo. Los cuidadores de } \\
\text { bajos ingresos experimentan más carga que los } \\
\text { cuidadores con mayores ingresos }\end{array}$ \\
\hline $\begin{array}{l}\text { Monin, } \\
\text { Joan et al. }\end{array}$ & $\begin{array}{l}\text { 2009/ } \\
\text { EEUU }\end{array}$ & $\begin{array}{l}\text { Establecer la relación entre la } \\
\text { exposición al sufrimiento del } \\
\text { receptor de cuidados y las } \\
\text { experiencias emocionales de los } \\
\text { cuidadores. }\end{array}$ & $\begin{array}{l}\text { Adultos mayores } \\
\text { con enfermedades } \\
\text { crónicas }\end{array}$ & $\begin{array}{l}\text { el género, la cercanía de la relación, la eficacia del } \\
\text { cuidado y las diferencias individuales en la } \\
\text { regulación de las emociones moderan los procesos } \\
\text { de afrontamiento. }\end{array}$ \\
\hline $\begin{array}{l}\text { Seltzer, } \\
\text { Marsha } \\
\text { Mailick et } \\
\text { al. }\end{array}$ & $\begin{array}{l}2000 / \\
\text { EEUU }\end{array}$ & $\begin{array}{l}\text { Identificar los tipos de } \\
\text { transiciones de cuidado } \\
\text { experimentadas por esposas e } \\
\text { hijas de personas mayores }\end{array}$ & $\begin{array}{l}\text { Adultos mayores } \\
\text { a } 60 \text { años con } \\
\text { demencia, } \\
\text { enfermedad } \\
\text { cardíaca, } \\
\text { Accidente } \\
\text { Cerebrovascular, } \\
\text { Artritis y diabetes }\end{array}$ & $\begin{array}{l}\text { Las hijas tenían más probabilidades de asumir el } \\
\text { rol de cuidadoras que las esposas, pero el impacto } \\
\text { de ingresar al rol fue más significativo para las } \\
\text { esposas. Después de convertirse en cuidadoras, las } \\
\text { esposas disminuyeron su participación en las } \\
\text { actividades de ocio, la percepción de la calidad de } \\
\text { las relaciones familiares y la satisfacción } \\
\text { conyugal. }\end{array}$ \\
\hline
\end{tabular}

Tema: Trayectoria y dinámica del rol como cuidador novel a lo largo del tiempo

$\begin{array}{ll}\text { Penrod, } & 2011 / \\ \text { Janice } & \text { EEUU }\end{array}$

Tang, 2014/

Siew et al. China

Carpentier, 2010/ Normand Canadá et al.

Chadiha, 2011/

Letha A EEUU

et al. como las describen los
Describir las interacciones sociales, el entorno de los cuidadores para comprender e identificar tipologías de entrada en la trayectoria del cuidador de Alzheimer.

Describir las variaciones en las trayectorias de los cuidados, tal cuidadores familiares informales que brindan cuidados al final de la vida

Caracterizar el impacto físico, psicológico, espiritual y calidad de vida, de las personas con cáncer en su último año de vida.

Personas con Alzheimer

Insuficiencia Cardiaca, EPOC, Falla renal.

Cáncer terminal

Establecer diferencias entre cuidadores urbanos y rurales de afroamericanas

Adultos mayores de 65 años afroamericanos
El tema unificador de los cuidadores al final de la vida se soportó en la búsqueda dęlnormalidad, durante su experiencia en escenarios de muerte anticipada, inesperada durante las fases de exacerbación y tratamiento de la enfermedad.

Los cuidadores deben lidiar con síntomas como angustia, depresión, ansiedad, carga percibida y mayor dependencia funcional en los receptores de cuidado durante los meses previos al fallecimiento.

Los cuidadores sonquienes detectan los primeros síntomas de la enfermedad, son generalmente conyugues del paciente, algunos tienen una experiencia previa de enfermedad, tiene una pequeña redes social y familiar. Algunos encuentran formas de superar las dificultades y dialogar, las reuniones y discusiones aumentan su reflexividad y la cooperación se convierte en una forma eficaz de resolver problemas.
Los cuidadores primarios que viven solos se encuentran de forma más frecuente en contextos rurales, pueden enfrentar tareas de cuidado muy exigentes, que se relacionan con la necesidad de asistencia diaria 


\begin{tabular}{|c|c|c|c|c|}
\hline Autor & $\begin{array}{l}\text { Año/ } \\
\text { País }\end{array}$ & Objetivo & $\begin{array}{l}\text { Situación de } \\
\text { dependencia }\end{array}$ & Rol del cuidador Familiar \\
\hline $\begin{array}{l}\text { Giovannet } \\
\text { ti, Erin } \\
\text { et al. }\end{array}$ & $\begin{array}{l}2010 / \\
\text { EEUU }\end{array}$ & $\begin{array}{l}\text { Establecer el enfoque para } \\
\text { identificar y definir a los } \\
\text { cuidadores de adultos } \\
\text { discapacitados de sesenta y } \\
\text { cinco años o más }\end{array}$ & Adultos mayores & $\begin{array}{l}\text { La forma en que se identifican a los cuidadores y } \\
\text { cómo se definen las discapacidades para } \\
\text { identificar a los beneficiarios de los cuidados } \\
\text { afecta profundamente el número estimado de } \\
\text { cuidadores y, por lo tanto, la implementación de } \\
\text { políticas nacionales destinadas a mejorar sus } \\
\text { experiencias y bienestar. }\end{array}$ \\
\hline
\end{tabular}

Freedman, 2014/

Vicki

EEUU

Identificar las necesidades de cuidado que surgen a lo largo

et al. del proceso de envejecimiento
Adultos mayores

Los cuidadores proporcionan ayuda con 3 o más actividades de autocuidado o movilidad, específicamente las relacionadas con alimentación e higiene corporal

\section{Tema: Transiciones en el rol de cuidador familiar novel}

$\begin{array}{ll}\text { Black, 2013/ } & \text { Betty } \\ \text { BeUU }\end{array}$

et al.

$\begin{array}{ll}\text { Betts, } & \text { 2006/ } \\ \text { Kathryn } & \text { EEUU }\end{array}$

et al.

Plank,

Angelika

2012/Ita

et al.

$\begin{array}{ll}\begin{array}{l}\text { Donorfio, } \\ \text { Laura } \\ \text { et al. }\end{array} & \begin{array}{l}\text { 2006/ } \\ \text { EEUU }\end{array} \\ & \\ \text { Cecil, } & \begin{array}{l}2013 / R e \\ \text { Rosanne } \\ \text { ino }\end{array} \\ \text { et al. } & \text { Unido }\end{array}$

Haley, 2009/

William E. EEUU

et al.

Kim, 2009/

Youngmee EEUU

et al.
Determinar la prevalencia de necesidades insatisfechas en una muestra de personas con demencia que residen en la comunidad y sus cuidadores informales

Describir los primeros cambios en las relaciones familiares posterior al deterioro cognitivo.
Demencia

Demencia

(a)
Neurocirugía, enfermedad neurológica durante la transición del hospital al hogar.

Explorar las expectativas, motivaciones filiales, cómo se cumplen los acuerdos entre madres e hijas cuidadoras.

Explorar las formas de cuidado y el afrontamiento entre los un accidente cerebrovascular.

Determinar la prevalencia, el estrés y el beneficio percibido, en cuidadores de adultos con Enfermedad Cerebrovascular

Investigar el impacto del cáncer desde la perspectiva de los cuidadores familiares, y comparar la carga y el estrés entre cuatro tipos de cuidadores.
Secuelas de

Mujeres adultas frágiles

Enfermedad

Cerebrovascular

Secuelas de Enfermedad Cerebrovascular

Cáncer, Diabetes, Demencia y Adultos Mayores frágiles
El $85 \%$ de los cuidadores tenía necesidades insatisfechas derivadas de la falta de recursos y educación sobre cómo la enfermedad afecta a las personas, la disponibilidad de servicios comunitarios y habilidades para cuidadores.

Asumir el rol de cuidador implica responsabilidadesque consiste principalmente en la toma de decisiones y la supervisión. Surgen sentimientos de frustración, resentimiento, dolor y privación relacional, junto con una mayor protección y ternura hacia la persona con demencia. La mayoría de los participantes eran ambivalentes acerca de buscar o aceptar ayuda de otros y parecían querer mantener ese estado la mayor parte del tiempo.

Los cuidadores se sierten responsables detodo, cumplir numerosos compromisos y diferentes roles sociales. Referían la necesidadde esperanza, confianza y seguridad durante la transición del hospital al hogar. La decisión de cuidar a un paciente en casa se asocia con sentimientos ambivalentes

En el proceso de transición se dan se dan cuatro procesos que se fundamentan en el darse cuenta de que es un cuidador, definir las funciones redefinir la relación de cuidador y aceptar la relación.

La complejidad de la enfermedad y su impacto en el rol del cuidador; los factores extrínsecos que sustentan el escenario del cuidado; y los factores intrínsecos que ayudan al cuidador a afrontar el nuevo rol.

Variaciones en el estado de ánimo depresión soledad, ansiedad, problemas de memoria, el cuidado físico; son las situaciones que más generan estrés en los cuidadores.

Dentro de los beneficios de brindar cuidado, se encuentra el apreciar más la vida.

Los cuidadores de personas con cáncer y demencia informaron mayores niveles de carga física y angustia psicológica ya que proveen más horas de cuidado por semana relacionadas con actividades de la vida diaria y cuidado con la eliminación urinaria. 


\begin{tabular}{|c|c|c|c|}
\hline Autor & $\begin{array}{l}\text { Año/ } \\
\text { País }\end{array}$ & Objetivo & $\begin{array}{l}\text { Situación de } \\
\text { dependencia }\end{array}$ \\
\hline $\begin{array}{l}\text { Pereira, } \\
\text { Helder } \\
\text { et al. }\end{array}$ & 2011 & $\begin{array}{l}\text { Comprender la experiencia } \\
\text { vivida de individuos que } \\
\text { asumen el papel de cuidadores } \\
\text { informales después de un } \\
\text { evento inesperado que involucra } \\
\text { a un familiar. }\end{array}$ & $\begin{array}{l}\text { Cáncer, Accidente } \\
\text { cerebrovascular, } \\
\text { Lesión cerebral, } \\
\text { Demencia }\end{array}$ \\
\hline $\begin{array}{l}\text { Buschenfe } \\
\text { Id, Karin } \\
\text { et al. }\end{array}$ & $\begin{array}{l}\text { 2009/ } \\
\text { Reino } \\
\text { Unido }\end{array}$ & $\begin{array}{l}\text { Investigar las experiencias de } \\
\text { las parejas de sobrevivientes de } \\
\text { un accidente cerebrovascular }\end{array}$ & $\begin{array}{l}\text { Accidente } \\
\text { cerebrovascular }\end{array}$ \\
\hline
\end{tabular}

Schulz, 2008/

Richard EEUU

et al.

$\begin{array}{lll}\begin{array}{l}\text { Poort, } \\ \text { Hanneke } \\ \text { et al. }\end{array} & \begin{array}{l}\text { 2016/ } \\ \text { Holanda }\end{array} & \begin{array}{l}\text { Establecer los predictores de } \\ \text { fatiga y acuerdo a lo largo del } \\ \text { tiempo }\end{array} \\ \begin{array}{l}\text { Beach, } \\ \begin{array}{l}\text { Scott R } \\ \text { et al. }\end{array}\end{array} & \text { EEUU } & \begin{array}{l}\text { Establecer los cambios en la } \\ \text { salud del cuidador de un } \\ \text { conyugué con discapacidad }\end{array}\end{array}$

Dunkle, 2013/

Ruth E $\quad$ EEUU

et al.

Establecer la asociación entre la transición al rol de cuidador y

los síntomas depresivos salud física y mental en cuidadores
Demencia

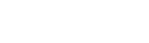

Cáncer

Adultos mayores de 65 años

Adultos mayores

per

,
personas con limitación en las actividades de la vida diaria, tienenmás síntomas depresivos que los no cuidadores. Encontrándose diferencias en los roles desde la perspectiva de género.

$\begin{array}{lll}\text { Välimäki, } & \text { 2012/ } & \begin{array}{l}\text { Describir los cambios y la } \\ \text { Tarja }\end{array} \\ \text { et al. } & \text { Finlandiación de vida de los } \\ \text { cuidadores familiares durante el } \\ \text { primer año después del } \\ \text { diagnóstico de la enfermedad }\end{array}$

Alzheimer

Los cuidadores familiares enfrentan desafíos en su orientación de vida, el entorno personal, la cohesión familiar y la concepción del futuro cambian. A su vez buscan encontrar elementos que ayuden a armonizar sus vidas y construir un nuevo futuro.

\begin{tabular}{|c|c|c|}
\hline $\begin{array}{l}\text { Silva- } \\
\text { Smith, } \\
\text { Amy L. } \\
\text { et al. }\end{array}$ & $\begin{array}{l}2007 / \\
\text { EEUU }\end{array}$ & $\begin{array}{l}\text { Describir el proceso asociado } \\
\text { con la preparación y el } \\
\text { comienzo de un nuevo rol de } \\
\text { cuidador, después de un } \\
\text { accidente cerebrovascular de un } \\
\text { miembro de la familia }\end{array}$ \\
\hline
\end{tabular}

Accidente cerebrovascular

Adulto mayor con dependencia

Moral- 2018/ Fernández, España Lourdes et al.
Describir el proceso inicial a través del cual las personas se convierten de manera inminente en cuidadoras de un familiar anciano dependiente. grave o total de

\section{moderada} acuerdo con el índice de Barthel
La reestructuración de la vida para el cuidado, se asoció con dimensiones como; la vida diaria, la gestión de múltiples roles, la relación on el receptor de cuidado, las esperanzas, planes futuros, y el tiempo para uno mismo. El proceso de esperar, reorganizar y estabilizar explica el proceso de reestructuración.

El cuidador pasa por una fase inicial de cambios, en la que asume nuevas actividades; una segunda fase cargada de emociones, en la que las necesidades y consecuencias emergen en los cuidadores; y una tercera fase que enfatiza la aceptación como estrategia de afrontamiento y la incertidumbre como expectativa de futuro. 


\begin{tabular}{|c|c|c|c|c|}
\hline Autor & $\begin{array}{l}\text { Año/ } \\
\text { País }\end{array}$ & Objetivo & $\begin{array}{l}\text { Situación de } \\
\text { dependencia }\end{array}$ & Rol del cuidador Familiar \\
\hline
\end{tabular}

\section{Tema: Participación en la toma de decisiones y el alcance de las responsabilidades}

Edwards, 2012/ Comprender el proceso de toma Cáncer en etapa Susanna Canadá de decisiones que ocurre entre avanzada et al. una persona en etapa final de la vida y su cuidador familiar.

Garvelink, 2016/ Mirjam M Canadá et al.

Martin 2016/ Revelar la experiencia de los Martin J España cuidadores familiares que et al. atienden a un paciente terminal en su domicilio.
Demencia, cáncer

Cáncer en etapa avanzada
Evaluar la efectividad de las participación de los cuidadores en la toma de decisiones

El objetivo central del cuidador $r$ está en acompañar a su familiar en esta fase terminal, en un proceso que inicia con la búsqueda de respuestas a los problemas que se presentan. A medida que el paciente y el cuidador se adaptan a la nueva realidad, comienzan a hacer un balance de su situación.

\section{Tema: Dominios e impactos del cuidador familiar novel}

Williams, 2012

Sharon EEUU

et al.

LI, 2018/

et al.

Moreno-

Cámara,

Sara et al.

2016/

España

Darragh, 2015/ Amy R. EEUU et al.

Suzuki, 2016/ Kishiko Japón et al.

Pope, 2017/ Natalie EEUU et al.
Identificar las prácticas de autocuidado entre los cuidadores familiares y las relaciones entre el autocuidado personal, el estrés percibido y otras variables de salud
Identificar y analizar los

problemas que surgen en el proceso de adaptación de la persona cuidadora a los cambios durante el cuidado familiar a una persona afectada por demencia

Adultos con enfermedad terminal.

Cáncer depresión en la diada paciente cuidador y su impacto en la Caracterizar la carga del cuidado y el malestar musculoesquelético asociado con el cuidado de adultos con discapacidad física crónica

Describir el efecto del dolor lumbar en la vida diaria de las mujeres cuidadoras.

Demencia

Discapacidad física y crónica que afecte la movilidad

Enfermedad cerebrovascular Demencia, Parkinson, Cáncer

Enfermedad crónica discapacitante
Los cuidadores manifiestan necesidades insatisfechas de información, discusiones sobre valores y preferencias, necesidad de apoyo en la toma de decisiones compartidas relacionadas con los cuidados al final de la vida, elecciones de tratamiento.

La experiencia del cuidadorincluye; el aprendizaje del diagnóstico: incertidumbre sobre el futuro y las perspectivas de muerte; sentir la carga física y emocional del cuidado; experimentar una vida limitada; redefinir la relación con la persona cuidada.

Los cuidadores participan tanto en tareas directas como indirectas de seguimiento y gestión del cuidado. Quieren participar en la toma de decisiones y acompañar a su familiar sobre todo cuando el curso de la enfermedad no es estable.

Los cuidadores experimentan un grado similar de ansiedad y depresión al que viven los receptores de cuidado lo cual se relaciona con la edad, el sexo, nivel de información sobre la enfermedad el tratamiento y la cantidad de tiempo dedicada al cuidado cada día.

Existen barreras y facilitadores en el proceso de adaptación del cuidador a su nuevo rol. La persona cuidadora desempeña su rol en una realidad caracterizada por el cambio, tanto personal como de la persona a la que cuida, su contexto social y cultural.

Los cuidadores refieren altos niveles de esfuerzo físico y malestar musculoesquelético, derivadas de la realización de actividades relacionadas con la movilidad, la suplencia de necesidades básicas, el entorno físico, lo cual afecta su salud física

Los síntomas musculoesqueléticos como el dolor lumbar se relaciona con la dificultad para realizar actividades de la vida diaria, mayor carga percibida, síntomas depresivos afectando la continuidad del cuidado.

El autocuidado se asocia de forma inversamente proporcional con el estrés y el dolor percibido y se asocia directamente con el bienestar emocional y la salud en general.

Fuente: Datos del estudio 2020. 
Sobre los 42 estudios incluidos en la revisión, 21 fueron realizados en EE. UU, 6 en España, 2 en Reino Unido, 3 en Canadá y los 10 restantes en otros países. Dentro de la característica de los participantes incluidos, se encontró que la edad de los cuidadores estuvo entre los 16 y 90 años, dentro de las condiciones que generaron discapacidad a corto y largo plazo, con demanda de cuidado, se identificaron condiciones como el accidente cerebrovascular, las lesiones cerebrales de diferente causa, el cáncer y las enfermedades neurodegenerativas entre ellas la demencia y el Alzheimer.

De acuerdo con los resultados, obtenidos del proceso de síntesis de las diferentes investigaciones, surgieron 5 temas principales, como son: las tendencias sociodemográficas de las personas que asumen el rol del cuidador familiar novel, la trayectoria y la naturaleza dinámica del cuidado a lo largo del tiempo, las transiciones en el rol, la toma de decisiones y el alcance de las responsabilidades y por último, los dominios e impactos en el cuidador familiar novel. El proceso de convertirse en cuidador novel de un familiar en situación de dependencia se presenta en la figura 2.

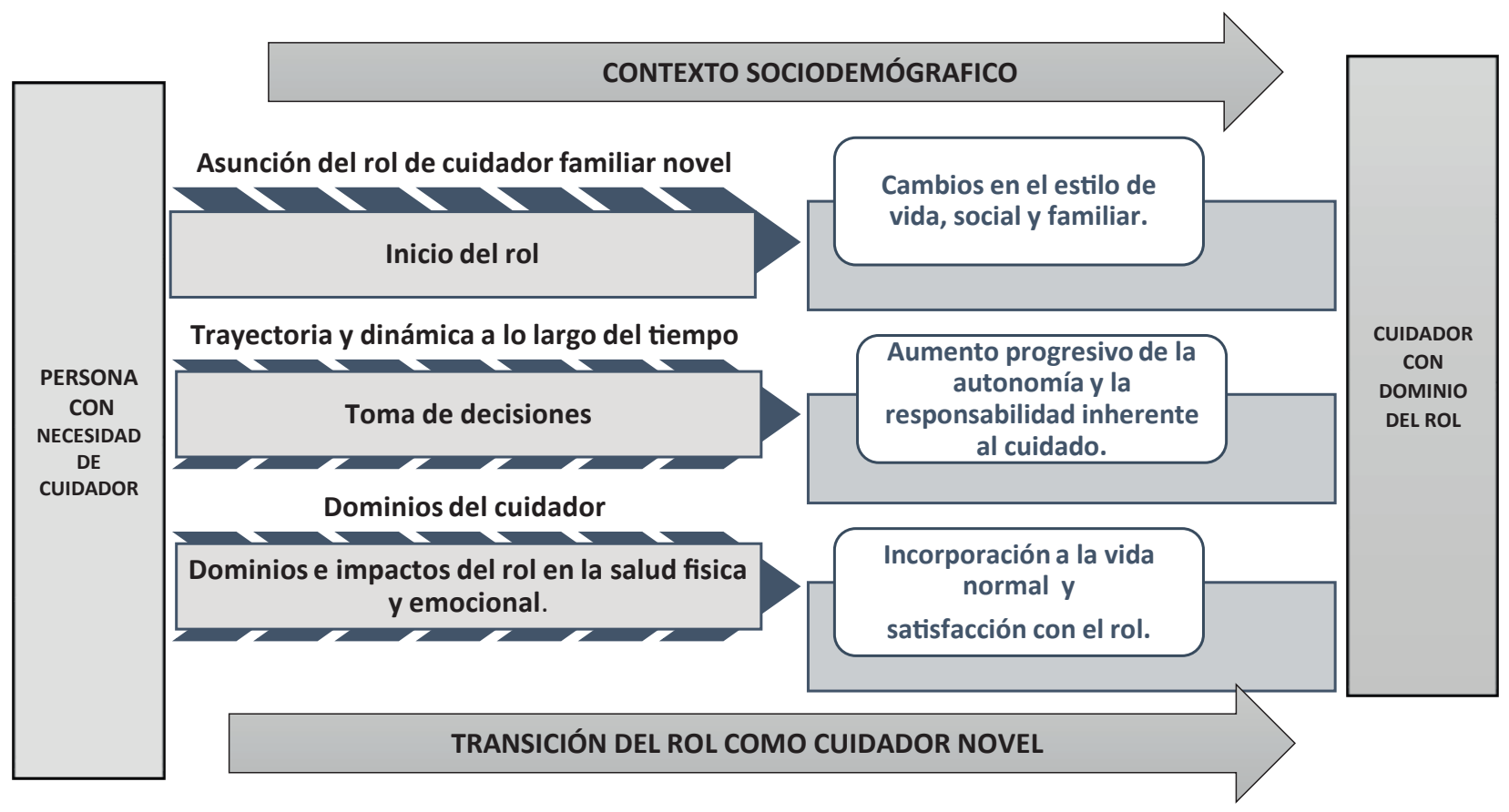

Figura 2. Diagrama del proceso de convertirse en cuidador novel de una familiar en situación de dependencia.

\section{Tendencias sociodemográficas de las personas que asumen el rol del cuidador familiar novel}

El perfil del cuidador familiar novel, está determinado por el sexo, la edad, el estado civil, el nivel educativo y el vínculo familiar. Durante años, la responsabilidad de cuidar se ha visto como un trabajo atribuido a las mujeres, en la actualidad esta proximidad sigue existiendo, ya que a ella se le adjudican valores propios del cuidado femenino, como son la entrega, la constancia, el sacrificio y la calidad emocional, de forma que son las mujeres madres, hijas, esposas, nueras, nietas e hijastras, quienes asumen con mayor frecuencia el rol de cuidador familiar novel ${ }^{18,19}$; sin embargo, en las últimas cuatro décadas la participación de las mujeres en la fuerza laboral es cada vez mayor, por lo tanto, están menos disponibles para el cuidado ${ }^{20}$, y tienen mayores presiones para equilibrar el trabajo, el cuidado y otras responsabilidades familiares, por lo 
anterior, se evidencia una creciente proporción de hombres como cuidadores y de instituciones, que brindan cuidad o formal para personas dependientes, las cuales se financian con los recursos propios de los residentes y sus familias, por lo que es difícil que adultos con recursos limitados tengan acceso a la atención institucional.

La edad del cuidador novel, influye en la forma como se asume el compromiso de cuidar, esta puede variar entre personas muy jóvenes hasta adultos mayores, quienes brindan atención a cónyuges, padres, abuelos, hermanos e hijos; cuando el cuidador es un adulto mayor, en general tiene cierto nivel de limitación física, cognitiva y enfermedades crónicas relacionadas con la edad, lo que lo predispone a mayor cansancio con su rol; los adultos entre 45 y 69 años representan casi la mitad de los cuidadores de uno o ambos padres, suegros, cónyuge u otros familiares, en general lo hacen como una actividad de reciprocidad hacía el otro, en el caso de los jóvenes, se tiene más probabilidad de sentir que el cuidado es una obligación ${ }^{21}$ que se asume porque no hay otra opción y porque no han elegido libremente asumir el desempeño de este rol.

El estado civil, está estrechamente relacionado con la disponibilidad de cuidadores, apoyo social, y bienestar en general, los cónyuges desempeñen un papel importante en el cuidado, dado que contar con el apoyo de una pareja sentimental, facilita el afrontamiento efectivo del rol $^{22}$, se ha encontrado que las mujeres casadas tiene mayor probabilidad de asumir el rol que las divorciadas y solteras, ya que en ocasiones el cónyuge constituye la única opción real y disponible que se presenta para desempeñar el rol de cuidador ${ }^{23}$.

El nivel educativo del cuidador influye en la búsqueda, uso de apoyo profesional para aliviar la carga de cuidado y en la forma como se concibe y asume el rol, los cuidadores con mayor nivel educativo acceden a los servicios con mayor facilidad, debido a una mejor información sobre la ayuda disponible ${ }^{24}$. Se ha determinado que las personas jóvenes y con mayor nivel educativo que cuidan a una persona dependiente tienen mayor probabilidad de tener un empleo formal y remunerado, por lo que deben realizar mayores cambios en sus rutinas de vida para coordinar las responsabilidades laborales y de cuidado ${ }^{25}$, mientras que los cuidadores con un nivel de educación más bajo, usualmente tienen menos probabilidades de estar empleados, por lo tanto terminan asumiendo por completo el rol de cuidador novel ${ }^{23}$.

Por último, los cuidadores de personas dependientes suelen tener un vínculo familiar y viven cerca o con el receptor de la atención, principalmente son los padres, hijos, cónyuges, nietos, situación relevante, dado que quienes residen conjuntamente tienen un mayor riesgo de resultados físicos y psicológicos adversos ${ }^{26}$. La relación o vínculo familiar entre el receptor y cuidador, constituye una consideración importante a tener en cuenta, ya que la percepción de brindar cuidado por obligación, es más fuerte en las relaciones de parentesco cercano ${ }^{27}$, los cuidadores que no tienen otra opción a la de asumir este rol, experimentarán niveles más altos de tensión física, estrés emocional, y un peor estado de salud ${ }^{21}$.

\section{Trayectoria y dinámica del rol como cuidador novel a lo largo del tiempo}

La trayectoria y dinámica del rol, hace referencia al cuidado que se brinda a lo largo del tiempo, a pesar de compartir experiencias comunes, el rol de los cuidadores familiares noveles es variable y está determinado por la conformación y dinámica familiar, el momento en el cual se asume el rol y el tiempo o duración del mismo ${ }^{28,29}$. 
De forma, que la trayectoria del cuidado pasa a través de etapas que pueden ser lineales o no lineales, lo cual que se define por el deterioro cognitivo, funcional y/o progresivo del receptor de cuidado. El primer caso, ocurre cuando el cuidado es recibido por personas que presentan deterioro a lo largo del tiempo, como ocurre en las enfermedades neurodegenerativas como la demencia y el Alzheimer, o en enfermedades crónicas como el cáncer avanzado; en esta situación el rol de cuidador se desarrolla, se amplía en el transcurso del tiempo y se caracteriza por un aumento de responsabilidades ${ }^{30}$. Por el contrario, se considera no lineal, en aquellas situaciones en las que los receptores de atención, experimentan períodos de discapacidad a corto plazo o episódicos ${ }^{31}$, en este caso el rol del cuidador se implementa rápidamente y de manera intensa como ocurre en una enfermedad o lesión aguda, o puede aumentar y tiende a disminuir gradualmente a medida que existe una recuperación y permanece relativamente estable durante un largo período de tiempo.

El tiempo de duración y la intensidad del cuidado, cambia según el nivel de discapacidad y se relaciona con las dinámicas y el tipo de cuidador, bien sea primario o secundario; pues estos últimos, cuidan de manera intermitente o complementaria, por lo cual, a diferencia del cuidador primario, dedican menos horas y tienen una menor carga de atención ${ }^{32}$. Se estima que en promedio los cuidadores de personas que presentan tres o más necesidades de autocuidado o movilidad, dedican hasta 253 horas de cuidado por mes, lo que equivale a casi dos trabajos de tiempo completo ${ }^{33}$. El tiempo requerido para proporcionar cuidado es directamente proporcional al número de necesidades y grado de dependencia, por ejemplo pacientes con un nivel de demencia avanzado, pueden requerir supervisión constante para protegerlas de daños a sí mismas y a otros, incluso si pueden realizar algunas tareas domésticas o de cuidado personal ${ }^{34}$, de forma que la combinación particular de actividades de cuidado y compromisos de tiempo varía.

Con respecto a las tendencias en los patrones y estructura familiar, derivados de un mayor control de la natalidad, menor fertilidad y número de hijos, ha llevado a familias más pequeñas, de forma que el grupo potencial de cuidadores va a ser cada vez menor, si se compara con generaciones anteriores, donde las familias eran numerosas, lo que aumentaba la posibilidad de personas disponibles para este rol y genera que cada vez sea mayor la carga en quien lo ejerce $^{19}$.

En resumen, la trayectoria de cuidado se desarrolla con el tiempo, con los cambios en las necesidades de cuidado, la estructura y las relaciones familiares, lo que indica la necesidad de evaluación y reevaluación periódica del rol del cuidador familiar

\section{Transiciones en el rol de cuidador familiar novel}

Cuidar a una persona con una enfermedad y/o discapacidad, ocasiona una transición en la vida del cuidador que se desarrolla en fases; preliminar, se relacionada con el momento de entrada en el rol de cuidador, y se deriva de la presencia de un evento significativo gradual, repentino o intenso, como puede ser una lesión, enfermedad o discapacidad en un tercero, que genera un compromiso de cuidado $35,36,37$. En este contexto, el rol como cuidador, emerge a partir de la conciencia que se genera en la red social, de la presencia de una discapacidad significativa, que hace indispensable el cuidado. En general los motivos que llevan a los cuidadores a ejercer este rol, son diversos siendo el afecto, la obligación filial o conyugal los más destacados, a partir de lo cual, surge un compromiso y dedicación hacia el cuidado sin una comprensión clara de las implicaciones actuales y futuras ${ }^{38}$, acompañado de una serie de preguntas alrededor del tiempo requerido para satisfacer las necesidades, la complejidad del cuidado, la participación, el apoyo de otras personas, el cambio de roles dentro de la familia, la disponibilidad de recursos y el asesoramiento sobre todo en las primeras etapas del cuidado ${ }^{39}$. 
La fase inicial o de entrada, se caracteriza por la ambigüedad del rol, por un lado, es posible experimentar efectos positivos, que se relacionan con el significado, propósito de vida, satisfacción, gratitud y las recompensas o beneficios derivados de la experiencia de ser cuidador, como una manera de estar cerca y asegurarse de que el receptor recibe una buena atención, lo cual genera sentimientos como la apreciación de la vida, el crecimiento personal, mejora de la autoeficacia, la competencia o el dominio y la autoestima ${ }^{40,41}$. En contraste, por el incierto curso de la enfermedad y la discapacidad en el receptor de cuidado ${ }^{42}$, se puede experimentar preocupación, inseguridad, desconfianza o incertidumbre, las cuales se relacionan con la falta del conocimiento y habilidades para abordar las necesidades físicas, emocionales, psicológicas y espirituales de quien recibe el cuidado, a las cuales se asocia la fatiga mental, el agotamiento físico, la sobrecarga de trabajo, la falta de tiempo para sí mismo, ya que los cuidadores priorizan las necesidades del paciente sobre las propias $\mathbf{4 3}^{43,45}$.

Estudios demuestran, que a medida que aumenta la demanda de cuidado, se presenta una disminución significativa en el bienestar del cuidador, la cual es seguido por una recuperación lenta y progresiva, después de que el receptor del cuidado se recupera o fallece ${ }^{46,47}$. En el entorno social, el cuidador familiar novel, presenta una redefinición de las relaciones con el receptor del cuidado, cambios en las relaciones familiares y en las actividades sociales, que alteran la participación habitual en actividades de la vida y que termina en el aislamiento y el deterioro a largo plazo de las redes sociales ${ }^{27,48}$, las demandas de tiempo y energía del cuidado, pueden competir con las actividades laborales y de ocio. Por otra parte, se pueden presentar, cambios y/ o desequilibrios en el grado de reciprocidad en la relación cuidador-receptor, que se afecta de forma directa y proporcional a medida que aumentan la dependencia ${ }^{35}$.

Finalmente, la fase de consolidación del rol; en la que se asume la nueva normalidad, el cuidador afronta y se adapta a su nueva forma de vida, encuentra significado a los eventos y su experiencia, trascienden el dolor, el sufrimiento, la incertidumbre y se apropia de su nueva condición; sin embargo, en el contexto de las enfermedades crónicas, para algunos cuidadores la incertidumbre impregna toda la experiencia y aunque varía con el tiempo nunca desaparece por completo ${ }^{49}$.

Dada la naturaleza multifacética y compleja del rol de cuidador novel, la mayoría de las personas no está preparada para asumirlo; tradicionalmente, los cuidadores describen el aprendizaje por ensayo y error, lo que genera angustia y temor ante la posibilidad de cometer errores potencialmente irreversibles, por lo que la preparación para el cuidado es esencial, para que adquieran las competencias para un adecuado desempeño y les permitan la resolución de problemas $^{50}$.

La transición del cuidador, además de desarrollarse en las fases mencionadas, se afecta por los cambios en las necesidades de cuidado, las transiciones sociales y la diversidad en las estructuras, normas, valores y de las relaciones familiares.

\section{Participación en la toma de decisiones y el alcance de las responsabilidades}

Los cuidadores familiares noveles de personas dependientes, participan en la toma de decisiones para los receptores de cuidado, esta cooperación, implica para ambas partes la conjugación de aspectos como valores, preferencias, necesidades, objetivos, consideraciones religiosas, percepciones y habilidades ${ }^{37}$. La participación del cuidador familiar novel en la toma de decisiones, depende del grado de impedimento cognitivo y falta de autonomía del receptor de cuidado, y se manifiesta en toma de decisiones relacionadas con las opciones de tratamiento, con 
la atención de la enfermedad a nivel físico, psicológico, funcionamiento social, atención al final de la vida, la subrogación para manejar asuntos financieros y legales, administrar el dinero y los bienes personales ${ }^{51}$. La toma de decisiones está influida por el contexto social, la disponibilidad de recursos y opciones para elegir, la comunicación y las relaciones entre los miembros de la familia, el conocimiento y la comprensión de la situación actual de salud, y los deseos del paciente. La toma de decisiones puede generar en el cuidador, sentimientos negativos como arrepentimiento, dudas, deseo de revertir la decisión, decepción, incomodidad o impotencia 52 , por lo general el cuidador conoce íntimamente a la persona que cuida, y puede verse muy afectado por las decisiones tomadas; además, los cuidadores y familiares, pueden tener puntos de vista diferentes sobre el tipo de cuidado requerido y cómo se debe proporcionar, situación que lleva a conflictos en la toma de decisiones ${ }^{53}$.

\section{Dominios e impactos del cuidador familiar novel}

El rol del cuidador familiar novel, abarca varios dominios, que incluyen realizar las tareas domésticas como mantenimiento del hogar, preparación de alimentos, abastecimiento; además realiza el cuidado diario de su protegido, garantizando el baño, la alimentación, la eliminación, el apoyo para la movilidad y los desplazamiento; también ejecuta actividades técnicas y de asistencia en salud, que incluyen la adopción de estilos de vida saludable, la adherencia al tratamiento, el manejo de equipos de soporte bombas de infusión, succionadores, catéteres, sondas, la búsqueda de asistencia en salud médica controles médicos, además de la resolución de problemas administrativos relacionados con la seguridad social en salud y la vigilancia constante sobre el bienestar del receptor ${ }^{54}$. También proveen apoyo emocional y social, que se relaciona con la expresión de amor, empatía y confianza; proporcionan compañía, facilitan las actividades de ocio, el manejo y solución de conflictos familiares; es esta labor de apoyo emocional, es la que los cuidadores perciben como de mayor tiempo consumido.

En una fase inicial los cuidadores pueden encontrarse con la presencia de emociones en el paciente como la tristeza, la soledad, el enojo, los sentimientos de impotencia, minusvalía, la depresión y la ansiedad ${ }^{55,56}$, los cuales pueden pasar como sutiles e imperceptibles; sin embargo, a medida que pasa el tiempo y se agudiza la dependencia, estos son reconocidos de forma retrospectiva.

Se ha establecido que satisfacer las altas demandas de cuidado, es físicamente exigente, las acciones de cuidado como transferencias, levantamientos, soporte en actividades básicas de cuidado como baño, alimentación, vestido, eliminación, movimiento, ejercen presión física sobre el cuidador y pueden provocar lesiones musculoesqueléticas, dolor, tensión muscular y contusiones, situaciones que pueden ser más difícil de manejar en entornos domésticos, sin las condiciones adecuadas ${ }^{57,58}$, por lo que los cuidadores tienden a calificar su salud como más pobre, que los no cuidadores.

Para los cuidadores, el descuido de su propia salud, puede empeorar las enfermedades preexistentes o aumentar la vulnerabilidad a los problemas relacionados con el estrés. Las acciones de promoción de la salud y autocuidado pueden verse afectadas por la falta de tiempo y energía para cuidarse a sí mismo, hecho que se acentúa en ausencia de redes sociales ${ }^{59}$, la mala salud física del cuidador está estrechamente relacionada con una mayor carga, la presencia de síntomas depresivos, con las horas de cuidado, el número de tareas de cuidado, los meses en el rol de cuidador, así como con los impedimentos físicos, cognitivos y problemas del destinatario de la atención. 
En resumen, el dominio del cuidador familiar novel es amplio y requiere del compromiso, habilidades, conocimientos y uso de estrategias de afrontamiento, por quien lo ejerce, hecho que sumado a los avances tecnológicos de los últimos años, conlleva a una mayor complejidad del rol del cuidador, especialmente cuando este se asume por primera vez.

\section{Discusión}
El dominio del cuidador familiar novel es amplio y requiere del compromiso, habilidades, conocimientos y uso de estrategias de afrontamiento, por quien lo ejerce, hecho que sumado a los avances tecnológicos de los últimos años, conlleva a una mayor complejidad del rol del cuidador, especialmente cuando este se asume por primera vez.

El propósito de este Scoping Review, fue llevar a cabo una revisión exploratoria de la literatura existente, para determinar el estado actual de la investigación, en el perfil y el rol del cuidador familiar novel, para identificar tendencias y limitaciones en esta área temática.

Los resultados, se suman a la evidencia que demuestra un creciente cuerpo de investigación, a nivel internacional en este campo, ya que los cuidadores desempeñan un papel esencial en la atención de personas con dependencia, principalmente en países de bajos y medios ingresos ${ }^{60}$; donde concurre el aumento en el envejecimiento de la población y los cambios en los patrones de las enfermedades, con la baja capacidad, la falta de acceso a la atención formal de servicios estatales y los bajos recursos económicos para asumir los $\operatorname{costos}^{7}$.

Los resultados de este estudio, evidencian elementos que predisponen a factores adversos en el cuidador novel; incluidas algunas las condiciones de sexo y edad, la intensidad del cuidado, el tiempo destinado al mismo; la falta de elección para asumir el rol; el estado de salud físico, mental y emocional del cuidador. En esta revisión se identificó que la mayor parte de los cuidadores noveles son mujeres ${ }^{17,19}$, quienes ejercen su papel en una amplia gama de condiciones crónicas, terminales y / o discapacitantes; en general comparten este rol con otros roles sociales y familiares, pero en último, es en quienes recae principalmente la acción de cuidado, con el consecuente impacto en la salud física y mental.

Dado que el rol de cuidador novel, puede ser asumido por personas jóvenes o mayores, incluso hay quienes comparten la misma edad generacional que el receptor de cuidado, y que los estudios se han centrado en proveer información, fortalecer las habilidades básicas de cuidado, e intervenciones principalmente en los cuidadores familiares adultos, se deben desarrollar enfoques de apoyo por parte de Enfermería ${ }^{61}$; para aumentar la conciencia de las necesidades de los cuidadores jóvenes quienes también proporcionan atención ${ }^{37}$.

Tener una pareja que participe y apoye en las acciones de cuidado favorece el afrontamiento conjunto ${ }^{22,23}$ y constituye un desafío para la vida, que exige el aprendizaje, construcción y adaptación a una nueva forma de vida, los adultos jubilados con discapacidad física y/o cognitiva, reciben cuidado de sus cónyuges quienes aunque constituyen un importante recurso de apoyo social, tienen un mayor riesgo de estrés psicológico, fragilidad y menor calidad de vida ${ }^{47}$.

Estos hallazgos resultan importantes, para ser tenidos en cuenta por los profesionales de la salud, a la hora de comprender, identificar e intervenir en futuras investigaciones y en el contexto de la práctica clínica; dado que debido al alcance, importancia, compromiso de tiempo y la complejidad del rol del cuidador familiar novel, es esencial involucrarlo como integrante activo y red de apoyo para el cuidado a largo plazo, dentro de la atención en salud que se brinda a las personas en estado de dependencia ${ }^{62}$. 
Por otra parte, se reconoce la trayectoria y dinámica del cuidado, las circunstancias y contexto en los cuales el cuidador familiar novel asume su rol, que puede variar entre eventos de lenta progresión ${ }^{30,48}$, hasta episodios ocasionales, abruptos y a corto plazo ${ }^{36,39}$, en ambos casos se deben garantizar enfoques de intervención diferentes, que tengan en cuenta la etapa en el curso de la vida del cuidador, las habilidades y motivaciones individuales.

Asumir el rol de cuidador por primera vez, implica una transición, que se caracteriza por el desarrollo en un contexto desconocido, que altera las rutinas diarias, cargado de emociones y que confronta al cuidador con una constante incertidumbre frente al futuro, hechos que en conjunto afectan la salud y el bienestar. Estos cambios, requieren del cuidador adaptación, desarrollo de nuevas habilidades y capacidades y el uso de recursos de afrontamiento internos y externos $35,37,38$. Por lo que es pertinente que enfermería, identifique las expectativas y requerimientos de los cuidadores de adultos dependientes, y garantice el seguimiento al proceso de transición, como una forma integral de dar continuidad a la atención, proporcionando educación precisa sobre lo que pueden esperar, promoviendo el desarrollo de habilidades para manejar sus nuevos entornos y demandas de cuidado.

El rol del cuidador es cada vez más complejo, ya que implica brindar asistencia diaria en actividades básicas, proporcionar ayuda relacionada con la atención de salud ${ }^{54}$, tomar decisiones subrogadas, dar apoyo emocional entre otras ${ }^{63}$; lo que puede desencadenar en el cuidador sobrecarga y afectación de su desempeño ${ }^{64}$, aunque los cuidadores noveles asumen una amplia gama de roles y responsabilidades, generalmente lo hacen sin suficiente educación, capacitación o apoyo. La investigación actual, muestra que la disponibilidad y la preparación de los cuidadores pueden afectar la calidad y el curso de la atención que reciben los pacientes en el hogar, por lo que el profesional de enfermería, debe identificar las habilidades del cuidador novel, brindar soporte de forma continua y coordinada, con el fin de que este pueda implementar medidas tempranas tendientes a la restauración de aspectos funcionales, psíquico, educacional, social, profesional y ocupacional de la persona dependiente y a su vez propender por su propio cuidado ${ }^{65}$.

El profesional de enfermería, debe identificar las habilidades del cuidador novel, brindar soporte de forma continua y coordinada, con el fin de que este pueda implementar medidas tempranas tendientes a la restauración de aspectos funcionales, psíquico, educacional, social, profesional y ocupacional de la persona dependiente y a su vez propender por su propio cuidado ${ }^{65}$.

Esta revisión tiene implicaciones importantes para las personas y las familias, así como para los responsables de políticas estatales, proveedores de servicios sociales y de salud, empleadores y otros, especialmente a la luz de las consecuencias sociales que genera el reconocimiento que merecen los cuidadores familiares noveles, por su contribución al bienestar del creciente número de personas con limitaciones físicas y / o cognitivas en las etapas iniciales lo que implica facilitar una transición saludable para garantizar su bienestar.

Dentro de las consideraciones de tipo investigativo a tener en cuenta a partir de esta revisión, está la de indagar en países en vía de desarrollo el concepto de cuidador novel, pues sería importante explorar el papel de las redes de apoyo social en esta situación, así como las acciones o dinámicas llevadas a cabo para disminuir la carga del cuidador familiar novel, se requiere la evaluación de intervenciones centradas en la persona, adaptadas a las necesidades de los cuidadores, en entornos del mundo real incluida la atención domiciliaria, la atención primaria, los hospitales o redes de atención de adultos con dependencia. 


\section{Conclusiones}

Este scoping review describió los elementos relacionados con el rol del cuidador familiar novel. Al respecto se encontró que la demanda de cuidadores está aumentando significativamente, debido al envejecimiento de la población, prevalencia de enfermedades crónicas, condiciones que aumentan la probabilidad de tener un deterioro físico o cognitivo significativo o ambos.

El rol del cuidador es cada vez más complejo y exigente, los cuidadores familiares, especialmente mujeres, son las que en gran proporción asumen la responsabilidad de cuidar, el impacto que esto tiene en la salud física y mental es individual, y depende de las circunstancias personales familiares y del entorno.

La intensidad y la duración del cuidado y el nivel de discapacidad del receptor de cuidado se relacionan con efectos negativos para la salud, otros factores de riesgo incluyen, falta de elección para asumir el papel de cuidador, la mala salud física del cuidador y la falta de apoyo social.

Conflicto de intereses: Los autores declaran no tener conflicto de intereses.

Financiamiento: Estudio sin financiación.

\section{Referencias}

1. Cheng H, Chair S, Chau J. Effectiveness of a strength-oriented psychoeducation on caregiving competence, problem-solving abilities, psychosocial outcomes and physical health among family caregiver of stroke survivors: A randomised controlled trial. Int J Nurs Stud. 2018;87:8493. https://doi.org/10.1016/j.ijnurstu.2018.07.005

2. Davidson P, Abshire M, Paull G, Szanton S. Family caregivers: Important but often poorly understood. J Clin Nurs. 2018;27 23-24:4242-4. https://doi.org/10.1111/jocn.14654

3. World Health Organization. Current and future long-term care needs: An análisis based on the 1990 WHO study The Global Burden Disease and the International Classification of the Functioning, Disability and Health. Geneva, Switzerland; 2002. Disponible en: https://apps.who.int/iris/bitstream/handle/10665/67349/WHO_NMH_ CCL_02.2.pdf?sequence=1\&isAllowed=y

4. United Nations. Department of Economic and Social Affairs. Disability and Development Report. Realizing the Sustainable Development Goals by, for and with persons with disabilities. 2018. p. 258. Disponible en: https://www.un.org/development/desa/disabilities/ wp-content/uploads/sites/15/2019/07/disability-report-chapter2.pdf

5. Roth G, Abate D, Abate KH, Abay S, Abbafati C, Abbasi N, et al. Global, regional, and national age-sex-specific mortality for 282 causes of death in 195 countries and territories, 1980-2017: a systematic analysis for the Global Burden of Disease Study 2017. Lancet. 2018;392 10159. https://doi.org/10.1016/S0140-6736 18 32203-7

6. Anauati MV, Galiani S, Weinschelbaum F. The rise of noncommunicable diseases in Latin America and the Caribbean: challenges for public health policies. Lat Am Econ Rev 2015;24 11 . https://doi.org/ 10.1007/s40503-015-0025-7

7. United Nations, Department of Economic and Social Affairs PD. World Population Ageing 2019. New York; 2020. p. 1-64. Disponible en: https://www.un.org/en/development/desa/ population/publications/pdf/ageing/WorldPopulationAgeing2019-Report.pdf

8. Ministerio de Salud y Protección Social. Sala situacional de las Personas con Discapacidad [Internet]. 2018. p. 1-37. Disponible en: https://www.minsalud.gov.co/sites/rid/Lists/ BibliotecaDigital/RIDE/DE/PS/sala-situacional-discapacidad-junio-2018.pdf 
9. Jang, Soong-Nang Avendano M, Kawach I. Informal Caregiving Patterns in Korea and European Countries: A Cross-National Comparison. Asian Nurs Res. 2012;6 1 :19-26. https://doi.org/10.1016/j.anr.2012.02.002

10.Carreño S, Chaparro L. Adoption of the family caregiver role of the chronic patient: a tool to assess thetransition.InvestigAndin.2018;2036:39-54.https://doi.org/10.33132/01248146.968

11.Carretero S, Garcés J, Ródenas F, Sanjosé V. The informal caregiver's burden of dependent people: Theory and empirical review. Arch Gerontol Geriatr [Internet]. julio de 2009;49 1:74-9. https://doi.org/10.1016/j.archger.2008.05.004

12.Sautter JM, Tulsky JA, Johnson KS, Olsen MK, Burton-Chase AM, Lindquist JH. Caregiver Experience During Patients' Advanced Chronic Illness and Last Year of Life. J Am Geriatr Soc. 2014;62 6 :1082-90. https://doi.org/10.1111/jgs.12841

13.Arksey H, O'Malley L. Scoping studies: Towards a methodological framework. Int J Soc Res Methodol Theory Pract. 2005;8 1 :19-32. https://doi.org/10.1080/1364557032000119616

14.Pham MT, Rajić A, Greig JD, Sargeant JM, Papadopoulos A, Mcewen SA. A scoping review of scoping reviews: advancing the approach and enhancing the consistency. Res Synth Methods. 2014;5 $4: 371-85$. https://doi.org/10.1002/jrsm.1123

15.Santillán García A. Lectura crítica de la evidencia científica. Enf Cardiol. 2014;21 63 :15-8. Disponible en: https://www.enfermeriaencardiologia.com/wp-content/uploads/63_01.pdf

16.Peters M, Godfrey C, Mclnerney P, Munn Z, Tricco A, Khalil H. Scoping reviews. En: Aromataris, E. JBI Manual for Evidence Synthesis: JBI. 2020.406-451. Disponible en: https://synthesismanual.jbi.global.

17. Colquhoun HL, Levac D, O'Brien KK, Straus S, Tricco AC, Perrier L, et al. Scoping reviews: Time for clarity in definition, methods, and reporting. J Clin Epidemiol. 2014;67 12 :1291-4. http://dx.doi.org/10.1016/j.jclinepi.2014.03.013

18.Wolff J, Spillman B, Freedman V, Kasper J. A National Profile of Family and Unpaid Caregivers Who Assist Older Adults With Health Care Activities. JAMA Intern Med. 2016;176 3 :372-379. doi:10.1001/jamainternmed.2015.7664

19.Pinquart M, Sörensen S. Ethnic differences in stressors, resources, and psychological outcomes of family caregiving: A meta-analysis. Gerontologist. 2005;45 1:90-106.

https://doi.org/10.1093/geront/45.1.90

20.Toribio-Díaz ME, Medrano-Martínez V, Moltó-Jordácl J, Beltrán-Blascod I. Characteristics of informal caregivers of patients with dementia in Alicante province. Neurología. 2013;28 2 :95-102. https://doi.org/ 10.1016/j.nrl.2012.03.010

21.Del-Pino-Casado R, Frías-Osuna A, Palomino-Moral P, Martínez-Riera JR. Gender differences regarding informal caregivers of older people. J Nurs Scholarsh. 2012;44 4 :34957. https://doi.org/10.1111/j.1547-5069.2012.01477.x

22.Schulz R, Beach R, Cook T, Martire L, Tomlinson J, Monin K. Predictors and Consequences of Perceived Lack of Choice in Becoming an Informal Caregiver. Aging Ment Heal. 2012;16 6 :712-721. https://doi.org/10.1080/13607863.2011.651439

23.Godfrey W, Yorgason J, Zhang Y, Hicken B, Chen W, Rupper R. Variability in spousal perceptions of caregiving and its relationship to older caregiver health outcomes. J Gen Intern Med. 2018;33:1504-1511. https://doi.org/10.1007/s11606-018-4408-8

24.Martins G, Corrêa L, Caparrol AJ de S, Do Santos P, Brugnera LM, Gratão AC. Sociodemographic and health characteristics of formal and informal caregivers of elderly people with Alzheimer's Disease. Esc Anna Nery. 2019;23 2.

https://doi.org/10.1590/2177-9465-ean-2018-0327.

25.Lüdecke D, Mnich E, Kofahl C. The impact of sociodemographic factors on the utilisation of support services for family caregivers of elderly dependents - results from the German sample of the EUROFAMCARE study. Psycho-Social-Medicine. 2012;9. doi: 10.3205/psm000084 
26.Yakubu Y, Schutte DW. Caregiver attributes and socio-demographic determinants of caregiving burden in selected low-income communities in cape town, South Africa. J Compassionate Heal Care. 2018;5 3 . https://doi.org/10.1186/s40639-018-0046-6

27.Monin J k, Schulz R. Interpersonal effects of suffering in older adult caregiving relationships. Psychol Aging. 2009;24 3 :681-95. https://doi.org/10.1037/a0016355

28.Seltzer MM, Li L w. The dynamics of caregiving: Transitions during a three-year prospective study. Gerontologist. 2000;40 2 :165-178. https://doi.org/ 10.1093/geront/40.2.165

29.Penrod J, Hupcey J, Baney B, Loeb S. End-of-life caregiving trajectories. Clin Nurs Res. 2011;20 1 :7-24. https://doi.org/ 10.1177/1054773810384852

30.Tang S, Liu LN, Lin C-K, Chung JH, Hsieh CH, Chou W-C, et al. Trajectories of the Multidimensional Dying Experience for Terminally III Cancer Patients. J Pain Symptom Manag. 2014;48 5 :863-874.: https://doi.org/ 10.1016/j.jpainsymman.2014.01.011

31.Carpentier N, Bernard P, Gernier A, Guberman N. Using the life course perspective to study the entry into the illness trajectory: The perspective of caregivers of people with Alzheimer's disease. Soc Sci Med. 2010;70 10 :1501-8. https://doi.org/ 10.1016/j.socscimed.2009.12.038

32.Giovannetti E., Wolff J. Cross-survey differences in national estimates of numbers of caregivers of disabled older adults. Milbank Q. 2010;88 3 :310-49. https://doi.org/ 10.1111/j.1468-0009.2010.00602.x

33.Chadiha L, Feld S, Rafferty J. Likelihood of African American primary caregivers and care recipients receiving assistance from secondary caregivers: A rural-urban comparison. J Appl Gerontol. 2011;30 40 :422-42. https://doi.org/ 10.1177/0733464810371099

34.Freedman V, Spillman B. Disability and care needs among older Americans. Milbank Q. 2014;92 3 :509-41._https://doi.org/10.1111/1468-0009.12076

35.Black B, Johnston D, Rabins P, Morrison A, Lyketsos C, Samus QM. Unmet needs of community-residing persons with dementia and their informal caregivers: Findings from the Maximizing Independence at Home Study. J Am Geriatr Soc. 2013;61 12 :2087-95.

https://doi.org/ 10.1111/jgs.12549

36.Adams K. The transition to caregiving: The experience of family members embarking on the dementia caregiving career. J Gerontol Soc Work. 2006;47 3-4 :3-29.

https://doi.org/10.1300/J083v47n03_02

37. Bulley C, Shiels J, Wilkie K, Salisbury L. Carer experiences of life after stroke - A qualitative analysis.Disabil Rehabil.2010;32 17:1406-1413.https://doi.org/10.3109/09638280903531238

38.Plank A, Mazzoni V, Cavada L. Becoming a caregiver: new family carers' experience during the transition from hospital to home. J Clin Nurs. 2012;21 13-14:2072-82.

https://doi.org/ 10.1111/j.1365-2702.2011.04025.x

39.Donorfio L, Kellett K. Filial responsibility and transitions involved: A qualitative exploration of caregiving daughters and frail mothers. J Adult Dev. 2006;13 3 :158-167.

https://doi.org/ 10.1007/s10804-007-9025-4

40.Cecil R, Thompson K, Parahoo K, McCaughan E. Towards an understanding of the lives of families affected by stroke: A qualitative study of home carers. J Adv Nurs. 2013;69 8 :17611770. https://doi.org/10.1111/jan.12037

41. Haley W, Allen J, Grant J, Clay O, Perkins M, Roth D. Problems and benefits reported by stroke family caregivers: Results from a prospective epidemiological study. Stroke. 2009;40 6 :2129-2133. https://doi.org/10.1161/STROKEAHA.108.545269

42.Kim Y, Schulz R. Family caregivers' strains: Comparative analysis of cancer caregiving with dementia, diabetes, and frail elderly caregiving. J Aging Health. 2008;20 $5: 483-503$. https://doi.org/ 10.1177/0898264308317533

43.Pereira H, Rebelo MA. Sudden informal caregivers: the lived experience of informal caregivers after an unexpected event. J Clin Nurs. 2011;20 17-18:2448-57.

https://doi.org/ 10.1111/j.1365-2702.2010.03644.x 
44.Buschenfeld K, Morris R, Lockwood S. The experience of partners of young stroke survivors. Disabil Rehabil. 2009;31 20 :1643-1651. https://doi.org/ 10.1080/09638280902736338

45.Schulz R, Sherwood P. Physical and mental health effects of family caregiving. Am J Nurs. 2008;108 9 :23-7. https://doi.org/ 10.1097/01.NAJ.0000336406.45248.4C

46.Poort H, Peters M, Gielissen M. Fatigue in Advanced Cancer Patients: Congruence Between Patients and Their Informal Caregivers About Patients' Fatigue Severity During Cancer Treatment With Palliative Intent and Predictors of Agreement. J Pain Symptom Manag. 2016;52 3 :336-344. https://doi.org/ 10.1016/j.jpainsymman.2016.02.017

47.Beach S, Schulz R, Yee J, Jackson S. Negative and positive health effects of caring for a disabled spouse: Longitudinal findings from the Caregiver Health Effects Study. Psychol Aging. 2000;15 2 :259-71. https://doi.org/ 10.1037//0882-7974.15.2.259

48.Dunkle R, Feld S, Lehning A, Kim H, Shen H, Kim M. Does becoming an ADL spousal caregiver increase the caregiver's depressive symptoms?. Res Aging. 2014;36 6 :655-682. https://doi.org/ 10.1177/0164027513516152

49.Valimaki T, Vehvilainen-Julkunen K, Pietila A, Koivisto A. Life orientation in Finnish family caregivers' of persons with Alzheimer's disease: A diary study. Nurs Heal Sci. 2012;14 4 :480487. https://doi.org/ 10.1111/j.1442-2018.2012.00721.x

50.Silva-Smith A. Restructuring Life: Preparing for and Beginning a New Caregiving Role. J Fam Nurs. 2007;13 1 :99. https://doi.org/10.1177/1074840706297425

51.Moral-Fernández L, Frías-Osuna A, Moreno-Cámara S, Palomino-Moral P, Del-PinoCasado R. The first moments of the carer:The process of becoming a caregiver of a dependent elderly relative. Aten Primaria. 2018;50 5 :282-90.

https://doi.org/ 10.1016/j.aprim.2017.05.008

52.Edwards S, Olson K, Koop P, Northcott, H. Patient and Family Caregiver Decision Making in the Context of Advanced Cancer. Cancer Nurs. 2012;35 3 :178-86.

https://doi.org/10.1097/NCC.0b013e31822786f6

53.Garvelink M, Ngangue P, Adekpedjou R, Diouf N, Goh L, Blair L, et al. Synthesis of knowledge about caregiver decision making finds gaps in support for those who care for aging loved ones. Health Aff. 2016;35 4 :619-26. https://doi.org/ 10.1377/hlthaff.2015.1375

54.Moral-Fernández L, Frías-Osuna A, Moreno-Cámara S, Palomino-Moral P, Del-PinoCasado R. Primeros momentos del cuidado: el proceso de convertirse en cuidador de un familiar mayor dependiente. Aten Primaria. 2018;50 5 :282-90.

https://doi.org/ 10.1016/j.aprim.2017.05.008

55.Williams S, Zimmerman S, Williams C. Family Caregiver Involvement for Long-Term Care Residents at the End of Life. Journal of Gerontol. 2012;67 5 :595-604.

https://doi.org/ 10.1093/geronb/gbs065

56.Pérez-Ordoñez F, Frías-Osuna A, Romero-Rodríguez Y, Del-Pino-Casado R. Coping strategies and anxiety in caregivers of palliative cancer patients. Eur J Cancer Care. 2016;25 4. https://doi.org/10.1111/ecc.12507

57.Darragh A, Lavender S, Tanner J, Vogel K, Campo M. Musculoskeletal Discomfort, Physical Demand, and Caregiving Activities in Informal Caregivers. J Appl Gerontol. 2015;34 6:734-60. https://doi.org/ 10.1177/0733464813496464

58.Suzuki K, Tamakoshi K, Sakakibara H. Caregiving activities closely associated with the development of low-back pain among female family caregivers. J Clin Nurs. 2016;25 15-16 :2156-67. https://doi.org/ 10.1111/jocn.13167

59.Pope N, Giger J, Lee J, Ely G. Predicting Personal Self-Care in Informal Caregivers. Soc Work Health Care. 2017;56 $9: 822-39$. https://doi.org/ 10.1080/00981389.2017.1344755

60.Bright T, Kuper H. A Systematic Review of Access to General Healthcare Services for People with Disabilities in Low and Middle Income Countries. Int J Environ Res Public Heal. 2018;15 9 . https://doi.org/10.3390/ijerph15091879 
61.Sprung S, Laing M. Young carer awareness, identification and referral. Br J Community Nurs. 2017;20 8. https://doi.org/10.12968/bjcn.2017.22.8.398

62.Garcia-Ptacek S, Dahlrup B, Edlund A, Wijk H, Eriksdotter M. The caregiving phenomenon and caregiver participation indementia. Scand J Caring Sci. 2019;33:255-65. https://doi.org/ 10.1111/scs.12627

63.Florez E, Rivas E, Seguel F. Burden level in performing the role of family caregivers of elderly with severe dependence. Cienc y enfermería. 2012;18 $1: 29-41$ https://doi.org/ 10.4067/S0717-95532012000100004.

64.Teixeira MJ, Abreu W, Costa N, Maddocks M. Understanding family caregivers' needs to support relatives with advanced progressive disease at home: an ethnographic study in rural Portugal. BMC Palliat Care. 2020;19 73 . https://doi.org/ 10.1186/s12904-020-00583-4

65.Lethin C, Hallberg I, Karlsson S, Janlov A-C. Family caregivers experiences of formal care when caring for persons with dementia through the process of the disease. Scand J Caring Sci. 2016;30 3 :526-34. https://doi.org/ 10.1111/scs.12275 
